\title{
Technological Frames and Care Robots in Eldercare
}

\author{
Susanne Frennert ${ }^{1} \mathbb{D} \cdot$ Hedvig Aminoff ${ }^{2} \cdot$ Britt Östlund $^{2}$
}

Accepted: 26 February 2020 / Published online: 16 March 2020

(c) The Author(s) 2020

\begin{abstract}
Care robots are often portrayed as an exciting new technology for improving care practices. Whether these robots will be accepted and integrated into care work or not, is likely to be affected by the assumptions, expectations and understandings held by potential end users, such as frontline staff and the people that are cared for. This paper describes how the conceptual framework of technological frames was used to identify the nature of care robots, care robots in use and care robot strategy as shared group level assumptions, expectations and understandings of care robots among care staff and potential care receivers. Focus groups were conducted with 94 participants. These groups consisted of line managers, frontline care staff, older people and students training to become carers. The technological frame of the nature of care robots revealed two complementary components: care robots as a threat to the quality of care, and care robots as substitute for humans and human care, held together by imaginaries of care robots. The technological frame of care robots in use revealed aspects of prospective end-users' uncertainty of their ability to handle care robots, and their own perceived lack of competence and knowledge about care robots. In addition, the following potential criteria for successful use of care robots were identified: adequate training, incentives for usage (needs and motives), usability, accessibility and finances. The technological frame of care robot strategy was revealed as believed cost savings and staff reduction. The novelty of the results, and their relevance for science and practice, is derived from the theoretical framework which indicates that adoption of care robots will be dependent on how well societies succeed in collectively shaping congruent technological frames among different stakeholders and aligning technological development accordingly.
\end{abstract}

Keywords Care robots $\cdot$ Focus groups $\cdot$ Frontline care staff $\cdot$ Older people $\cdot$ Students $\cdot$ Attitudes $\cdot$ Values

\section{Introduction}

Higher standards of living, coupled with technical and medical developments, have led to an increase in life expectancy [1]. However, increased longevity introduces its own problems: many elderly people need help with daily activities [2]. In Sweden, this support is provided by relatives and homecare, funded by municipalities. Yet as the number of older people continues to grow, many homecare organisations face challenges in recruiting staff, and there is considerable concern about how quality care can be maintained. Care robots are frequently proposed as a solution to the problem [3-5].

Susanne Frennert

susanne.frennert@mau.se

1 Internet of Things and People Research Center, Department of Computer Science and Media Technology, Malmö University, Malmö, Sweden

2 KTH, School of Chemistry, Biotechnology, and Health, Stockholm, Sweden
Care robots are portrayed as a technological revolution in the sense that they allow for innovative applications in healthcare [6-9]. If care robots can be efficiently and successful adopted, they are predicted to serve as both a substitute for humans in situations where there are physical risks (e.g. lifting), and as a supplement, in situations where increased efficiency and productivity is desired (e.g. cleaning, delivering food, for daily activities, social and cognitive stimuli) [10]. In these ways, care robots are predicted to transform the performance of care work and as a consequence, new markets and new services are expected to develop [11].

However, care robots need to be used in order to have any impact. While this may seem obvious, there are numerous of examples of robotic applications that have limited uptake, despite robust and sound engineering [12]. One fundamental challenge to implementation and use is the failure to understand that adoption of technology in care settings is a socio-technical activity: everyday care practices (e.g. care for people of age) involve interaction and communication 
among humans and technology within complex organisational infrastructures and social settings [13]. Consequently, care robots cannot be treated as a purely technical issue $[14,15]$. People do not automatically start using technology or robots; individuals' behaviours and actions towards any technology will be affected by each person's priorities [16-19] and assumptions, expectations and understandings of the technology in question, such as perceptions about whether a technology can help them attain their goals or not $[20,21]$. Thus, the use of technology is not an automatic outcome of technical engineering, but is rather the result of behaviours affected by organisational culture, contexts and aspects of society [21-25]. As social practice theory emphasises, practices do not change by a technology per se. Instead, technology acceptance and usage evolves through changes, rearrangements and readjustments of the elements that hold a practice together (objects, infrastructures, competences, images and meanings) [26-29]. This tells us that care robots need to be not only functional and robust: it is imperative that end users, such as frontline care personnel, relatives and care receivers, also have a desire to use them in their homes and at work [10,30]. End users are pivotal for acceptance and wide-spread adoption of technology in healthcare [31-33]. Paradoxically, end-user groups are seldom involved in procurement $[34,35]$. Similarly, their voices are rarely heard in the development of care robots or in the media debate surrounding the use of robotic technology in healthcare. What attitudes do these end-users hold towards care robots? What opportunities and obstacles do they see?

This article approaches the assumptions, expectations and understandings of care robots held by potential end-users, specifically frontline care personnel and care receivers, from a sociotechnical perspective. We use the phrase assumptions, expectations and understanding since these concepts are interdependent and therefore can't be analysed separately. The analysis is based on mental models or cognitive structures (e.g. technological frames) in which assumptions, expectations and understandings are included [1]. Therefore, the presentation of the results is based on the analysis of technological frames and presented as such. The assumption is that end-users construct their own versions of the 'reality' of care robots rather than passively absorb a vision that is presented to them. Assumptions, expectations and understandings are seen as constituting the state between what is considered 'good' or 'bad' technologies and 'good' or 'bad' standards of care [36]. Thus, it is vital to gain insight into enduser attitudes towards care robots: the way end-users think, talk about and feel in regards to care robots can help predict whether care robots will be socially accepted or not $[37,38]$.

\subsection{Care Robots}

What is meant by the terms 'robot' and 'care robots'? There are different definitions of what a robot is: in general terms a robot is considered a device with differing levels of autonomy, and with ability to think, plan and sense its environment [39]. A care robot is a robot that is specifically designed for healthcare purposes [40]. Care robots exist in various forms and with various functions including physical, $\operatorname{cog}$ nitive, medical and psychosocial support [5]. There are few examples of care robots that are actually used in eldercare situations. One is Paro, a therapeutic robot designed to look like a seal; it reacts to touch and handling. Paro has been used and successfully diffused at nursing homes in Finland [41], the UK, Germany and Denmark $[42,43]$.

Most people are familiar with robots as they are depicted in media through films or television shows. These preconceptions of robots affect people's attitudes towards and expectations of care robots [44], and can sometimes generate disappointment when people experience robots in real life [45]. In 2015, a survey was carried out with almost 28.000 participants and it showed that a majority of Europeans are against the use of robots for older people [46]. However, research findings specifically regarding healthcare professionals' and older people's perceptions and attitudes to care robots are few and inconclusive [5, 11, 40, 44, 47, 48]. [49-51]. We do not yet know how the robotization of healthcare will unfold, but one thing is clear: technologies mediate human practices and experiences [49, 50, 52]. Care robots appear either as technological visions or in physical forms $[53,54]$. As such the target group do not only deal with care robots themselves but with promises, hopes, debates, promotions, worries and fears in regard to care robots. Leading to that the target group already have ideas what care robots are and how they fit (or not) into their habits, work and everyday life. In some sense they have already made sense of care robots (e.g. have technological frames of care robots). In order to provide more knowledge about end users' assumptions, expectations and understandings of care robots, this study focused on line managers, frontline care staff, older people and students training to be care staff in order to pursue the following three aims:

(1) To examine how prospective end-users, understand and interpret care robots.

(2) To explore how potential end-users make sense of care robots, and if the assumptions, expectations and understandings within the participating groups are sufficiently congruent for line managers, frontline care staff, older people and students to be conceived as homogenous social groups. 
(3) To frame the problem space and determine a course of action to address the complexities of care robots in care practices.

\section{Research Framework}

Sensemaking is a term to describe a process by which people extract cues from the environment and from other people, in order to understand them $[56,57]$. This process is a matter of identity: how we understand ourselves in relation to our environment. Sensemaking is a concept-driven process in which we make our best guess of what we see, or extract cues based on beliefs, expectations, knowledge and past experience. To paraphrase Ingold and Kurttila: humans do not discover a pre-existing world, they do not construct the world based on what they are, but on what they believe is possible due to assumptions, prior knowledge and expectations [58]. Perceived imaginary qualities or features of a new technology reflect possible relationships between objects and actors [59]. In this sense, the meanings that individuals give to new technologies are arbitrary, artificial and learned [60], and potential user's fears, hopes and imaginaries will affect their assumptions, expectations and understandings of new technologies. Thus, the way in which humans make sense of new technology such as care robots depends on the individual's socialisation and communities of practice [61]. How a potential user makes sense of a certain technology may change over time in response and adaption to new experiences, insights or knowledge.

The assumptions, expectations and understandings of a new technology such as care robots are not necessarily bound to an individual but can also be shared among members of a social group, organisation or practice. Orlikowski and Gash (1994) use the concept "technological frames" to describe shared core assumptions, expectations, and knowledge of information technology among members of a community or at a workplace [24]. A technological frame might be the result of professional or occupational training, as well as part of a socialisation process at a workplace or in a working practice. Orlikowski and Gash (1994) describe technological frames as individuals' mental models or cognitive structures. These may also be shared among members of a group, in parts or as a whole. Technological frames reveal how people make sense of a technological phenomenon and their mutual understanding. Orlikowski and Gash (1994) found three categories that characterise the interpretation of technology: the nature of technology (i.e. people's images of a technology and their understandings of the technology's functionality and capacity); technology in use (i.e. people's understanding of how they will use the technology at work); and technology strategy (i.e. people's understanding of why their work organisation has procured or deployed the technology, the expected outcomes and values from the organisation's perspective) [24]. The concept of technological frames and the three categories will be used in the analysis and discussion of the results.

As technologies are culturally and socially embedded, their materiality reflects the objectives and values of their producers $[62,63]$. These values may be shared among all members and groups of users. However, there may also be resistance and conflicts: developers' objectives and values may contrast with other social groups' objectives, since technology might affect how work is done and also the division of labour. Incongruent frames is a term to describe contrasting assumptions and understandings, or differences in assumptions and expectations of a technology among different groups [24]. In Bijker's example of the bicycle (Bijker, 1995), he shows how different social groups give different meanings to a technology and how the interpretation of an innovation is flexible, initially. Over time, however, interpretations become more stable and gradually reach a closure, at which point a dominant group's assumptions and expectations become representative and dominant [63].

Technological frames may also vary across different cultural and physical contexts. Comparative quantitative studies focusing on care personnel's attitudes and fears toward care robots in Finland versus Japan reveal that care personnel in Finland have more negative attitudes and fear towards the introduction of care robots in elderly care than their counterparts in Japan [64, 65]. Mavridis et al. (2012) conducted a survey investigating people's attitudes and opinions regarding robots in the middle east [66]. Their results show how religion and gender can have effects. Research on human-robot proxemics show that humans react differently to robots depending on the setting [67]. The mentioned studies show that attitudes and values towards care robots are socially and culturally embedded. It also indicates that knowledge and understandings of care robots can be expected to be situated [68].

In social media, robots are often portrayed as replacement for human workers in healthcare [69]. This can cause them to be perceived as a threat from a healthcare worker's perspective. However, a scoping review shows that there are limited studies actually delving into end-users' assumptions, expectations and understandings of care robots [70], and the authors argue that there is a need for care workers to be involved in the discussion about care robots in order to be able to influence how care robots may impact their work. This conclusion has been echoed by another study [71], and is one of the reasons why focus group methodology was used in this study.

The findings of this study are understood from an interpretive perspective, which contrasts to positivist approaches which assume that researchers can access and measure an objective reality through an appropriate study design. 
In the interpretive approach used in this study, people are seen as constructing their own realities, and performing them in everyday practices as actions [25]. Individuals co-construct, share and reproduce realities among each other through explanations, insights and descriptions of attitudes, beliefs and values. From this interpretive view, social reality cannot be seen as singular or objective [72, 73]. However, using technological frames is a way to generalize multiple perspectives by relating core assumptions, expectations, and understandings, in this case how perspectives of care robots are shared among prospective end-user groups of participants in the focus groups.

\section{Methods}

\subsection{Participants}

A series of focus groups were conducted with 94 participants, including line managers, frontline care staff, older people and students training to become care staff (Table 1). Potential participants were recruited by using the snowball principle [74], by contacting associations for older people, municipalities and healthcare colleges in Stockholm, Sweden. Participants were selected on the basis of suitability and diversity of the experience of care. While older people and students were relatively easy to recruit, line managers and frontline care staff were more challenging to recruit due to time restraints; a majority of those asked declined to participate.

\subsection{Study Design}

The purpose of the focus groups was to elicit attitudes about the use of robots in elder- and healthcare situations from a range of people working within eldercare, as well as potential eldercare receivers in Sweden. The focus group methodology was chosen because it allows meaning to be constructed through interactions [75]. The interactions between the participants in the focus groups allowed participants without prior experience of care robots to articulate their attitudes and perceptions of care robots, and for the researchers to explore the participants' views and opinions about care robots.

Table 1 Demographics of the focus groups participants

\begin{tabular}{llllll}
\hline Participants & Number & Age range & Mean & Female & Male \\
\hline Older people & 31 & $70-85$ & 76.8 & 17 & 14 \\
Line managers & 15 & $32-62$ & 47.6 & 12 & 3 \\
$\begin{array}{l}\text { Frontline care } \\
\quad \text { staff }\end{array}$ & 7 & $22-58$ & 41.2 & 5 & 2 \\
$\quad$ Students & 41 & $16-20$ & 17.8 & 34 & 7 \\
\hline
\end{tabular}

The focus group method involves focused group discussions about a specific subject that is selected by the researcher, in this case care robots. During focus groups, participants interact with each other and the researcher [76, 77]. According to Jayasekara (2012), focus group research is constituted of three components: (1) it is a method for collecting data, (2) the active interaction between the participants and between the participants and the researcher is the foundation of data, and (3) the researcher has an active role in moderating the group discussion [78]. Furthermore, not only do focus groups generate research data, they also provide opportunities for the participants to become engaged and learn about the subject [79]. In this sense, the focus groups in this study served as an opportunity for the participants to learn about advances in robotics in healthcare as well as to uncover the participants' priorities and desires, collect anecdotes and investigate reactions to care robots. It has been suggested that focus groups work best if they contain participants who have similar experiences, in order to promote comfort and avoid potential power struggles [80-83]. For this reason, each focus group contained only people from one of the recruited targeted groups: older people, frontline care staff, line managers and students training to become care staff. In addition, the groups were made to be fairly homogenous in terms of experience and work obligations.

The series of focus groups was led by a facilitator (first author), who directed the flow of questions and the video (Table 2). Other researchers observed and took notes during the focus groups (second and third author). Each focus group was recorded via voice memo on an iPhone. Written field notes were taken during and after each focus group session.

\subsection{Data Analysis}

The data was analysed in accordance with principles of qualitative data analysis $[84,85]$, in a sequence of steps. The audio recordings from the focus groups were repeatedly listened to in order to gain an overall understanding of the material. Then the first author searched the voice recordings for essential expressions concerning assumptions, expectation and understandings of care robots among each potential enduser group (e.g. older people, line managers, frontline care staff and students). These were then transcribed and logged in NVivo. Next, the first author coded the text into meaning units, wrote condensed meaning units and interpreted the underlying meaning; the condensed meaning units were examined in relation to similarities, variations and differences within each end-user group and between each end-user group. Shared assumptions, expectations and understandings of care robots of each group were grouped into three main categories (the nature of care robots; care robots in use; and care robot strategy [24]. The first and second author then independently reviewed the data by comparing the definition for each 
Table 2 The steps in which the focus groups were conducted

Step 1. Introduction and welcome

Step 2. A short video presentation of different robot applications in elder- and healthcare (e.g. medical robots for surgery (da Vinci robot), robots for autonomous transport of materials and supplies (HelpMate, Atheon TUG), telepresence robots (Giraff), exoskeletons, companion robots (Pepper, Buddy), humanoid robots (Enon, NAO), robots as motivational coaches (RoboCoach, Vizzy), robots as home assistants (Care-o-bot, Hobbit), therapeutic robots (Paro, JustoCat), social robots, and robots that lift and fetch objects (Toyota care assist robot).

Step 3. Online survey questions about general risks and opportunities of robots in elder- and healthcare: What general opportunities do you perceive with using robots in elder-and healthcare?

What general risks do you perceive with using robots in elder-and healthcare?

Step 4. Group discussion about the results of the previous step.

Step 5. Working in small groups, the participants were asked to describe and draw an image of their ideal robot, and explain its functions, appearance and user interactions.

Step 6. Group discussion about the participants' ideal robot.

Step 7. Online survey questions about particular and individual pre-requisites for use and barriers to adoption of care robots:

What hinders your adoption of a care robot?

What pre-requisite needs to be in place in order for you to adopt a robot?

Step 8. Group discussion about the results of the previous step.

Step 9. Wrap up.

code and example quotes from the data [86]. The function "coding comparison query" in NVivo was used to calculate percentage agreement. The kappa coefficient score was 0.923, which indicates a high percentage of agreement [86]. The final stage saw the authors come to a consensus regarding assumptions, expectations and understandings of each end user group and for each category. These were compared and modified with the answers from the online survey tool and the design sketches to verify and confirm the findings [85].

\subsection{Ethics}

The focus groups were conducted during autumn 2018 in Stockholm, Sweden and lasted about two hours each. The participants were informed about the study both in writing and verbally. They were informed that their participation was voluntary and that they could leave the focus group at any time without having to explain way. They were also informed that what was said during the focus group would not be traced back to them individually. The guidelines for research ethics issued by the Swedish Research Council [87] was followed. The research does not cover any sensitive information and therefore does not require ethical approval according to the Swedish regulations on research ethics [87].

\section{Results}

Our analysis revealed a number of congruent and incongruent technological frames among the groups of end-users in regard to care robots. The results are grouped into three categories:

- The nature of care robots: participants' images of care robots and their understandings of care robots' functionalities and capacities.

- Care robots in use: participants' understanding of how they will use care robots in care work.

- Care robot strategy: participants' understanding of why care robots are procured or deployed in care, the expected outcomes, and values from the organisation's perspective.

\subsection{The Nature of Care Robots}

The nature of care robots describes the participants' images of care robots and their understandings of care robots functionality and capacity.

\subsubsection{Care Robots as a Substitute for Humans and Human Care}

There were shared assumptions, expectations and understandings across all the groups that care robots could increase efficiency in the provision of care and patient services by changing and improving working conditions, and simultaneously reducing costs. As such, the participants described care robots as a substitute for humans and human care. Care robots were described as a means to do dirty, dangerous and monotonous tasks (e.g. cleaning, cooking, shopping, lifting, documentation), and as potential companions for care receivers by providing around-the-clock social and cognitive stimuli.

The nature of care robots was also addressed in the participants' sketches of their ideal robot. There were differences between the groups in their depictions of an ideal robot. Here incongruent frames become apparent. Most of the older participants sketched what could be called a servant robot, which could do cleaning, cooking and washing. The line managers designed robots that could perform documentation, quality assurance tasks and surveillance. The students designed humanoid robots that could carry out care tasks such as cooking and cleaning as well as provide social stimuli for care receivers. Similarly, the frontline care personnel designed robots for cognitive help for care receivers as well as robots that could help with heavy lifting and care receivers' hygiene needs. 


\subsubsection{Care Robots as a Threat to the Quality of Care}

Across all the groups, questions about the nature of care, care giving, care receiving, perspectives on aging and the quality of elderly care emerged. Participants had specific questions in regard to the concept of caring, such as:

- Which values and views of human life in relation to care robots should be predominant?

- How well do care robots help with care work?

- What is the nature of this kind of care work?

- What function should frontline care staff fill in elder- and health care?

- What are the risks with care robots?

There was apprehension that robots might lead to mechanised care, resulting in isolation and loss of physical human contact among the older people, frontline care personnel and students, Mechanised care was associated with care provided without flexibility and sensitivity to the individual's needs. Care robots were perceived as unable to easily adapt to altered circumstances and needs, while humans were perceived as superior in interpreting care situations and changed circumstances and adjusting accordingly to the specific needs of an individual care receiver.

While the line managers raised questions about patient safety in regard to care robots, the students, the frontline care staff and the older participants predominantly expressed issues relating to the quality of care. There appeared to be a shared understanding of the concept of care, which encompassed feeling concern for or taking charge of the well-being of others. The understanding of the concept of care and care practices appear very similar to the concept of altruism [88]: an unselfish concern for the wellbeing of others. For the frontline care staff, the students and the older participants, care involved mutual reliance, respect, consideration, and understanding between care receivers and care personnel as well as a human touch. In their eyes, care robots symbolise standardised care giving, which is not possible or feasible since care relationships between individuals cannot be generalised (Table 3). As one of the students said:

A care robot cannot provide the right kind of care, it does not have any empathy or understanding of the human care receiver. (Student, age 17, female)

\subsection{Care Robots in Use}

Care robots in use describes the participants understanding of how they will use care robots in care work or at home (older people).

\subsubsection{Lack of Control}

The high speed at which new technological innovations are developed frightened the participants across all groups. Several voiced distress about the difficulties of keeping up with technical developments and finding reliable sources of information; as a result, care robots and similar innovations made them feel that they lacked a sense of control.

In the focus groups with students, frontline care staff and older participants, insecurity about mastering care robots was expressed. Many of the participants mentioned fear and anxiety about lacking the technical skills necessary for handling care robots. The older participants mentioned prior experiences with technology that had complicated interfaces and were difficult to use; as a result, the technology ended up not being used at all. The frontline care staff and the students had similar experiences of complicated technologies and technical aids that were supposed to be used in care work and training practices that ended up unused due to technical difficulties. The frontline care staff also highlighted that care organisations often invest in technologies or changed working procedures without ensuring that proper training, competence development, initial involvement of care personnel, time and resources were provided.

Several students and frontline care staff expressed fear that problems with handling the robots would divert the attention of care staff from care receivers. Frontline care staff were especially worried about the potential misuse and malfunction of care robots. They and the students thought that there was a risk that care organisations focused too much on innovations and digital transformation, and that this would take precedence over spending time and effort to raise the status of care work and improve working conditions.

Among the older participants, care robots triggered ambivalent feelings about losing and gaining autonomy and independence. They thought that interdependence with robots may help an older individual to re-establish independence and autonomy. If such freedom and autonomy is achieved in the human relationship with robots, each individual can exercise power over the robots by making decisions that the robot obeys. However, the older participants also expressed fear about human interdependence with robots. Many of the concerns were driven by the perception of robots having the ability to be superior to humans, and thereby exercise their 'robotic' power over individuals. Robots were not perceived as 'evil' in such scenarios, but rather that people might become dependent on robots. Fears were expressed that care receivers might become extremely vulnerable and at risk in the case of a system breakdown, power outage or if the robots were hacked.

The older participants also raised questions about reliability, safety and responsibility: 
Table 3 Technological frames and the nature of care robots: the participants' image of care robots and their understandings of care robot's capacity and functionality

\begin{tabular}{|c|c|c|c|c|}
\hline Nature of care robots & Older people & Line managers & Frontline care staff & $\begin{array}{l}\text { Students who are training } \\
\text { to become frontline care } \\
\text { staff }\end{array}$ \\
\hline $\begin{array}{l}\text { Substitute to humans and } \\
\text { human care }\end{array}$ & $\begin{array}{l}\text { Improved working } \\
\text { conditions for elder- and } \\
\text { healthcare professionals } \\
\text { Increased patient services } \\
\text { Improved delivery of care } \\
\text { with constant quality } \\
\text { Patient independence and } \\
\text { integrity } \\
24 / 7 \text { service and } \\
\text { assistance } \AA\end{array}$ & $\begin{array}{l}\text { Improved performance } \\
\text { quality } \\
\text { New work procedures } \\
\text { More efficient } \\
\text { administration } \\
\text { To cater to the needs of } \\
\text { care receivers and care } \\
\text { staff } \\
\text { Time saving } \\
\text { Surveillance of care } \\
\text { receivers and staff }\end{array}$ & $\begin{array}{l}\text { Simplify care work } \\
\text { Additional time for care } \\
\text { receivers } \\
\text { To support physical care } \\
\text { work and cleaning } \\
\text { responsibilities } \\
\text { To support the cognitive } \\
\text { abilities of the care } \\
\text { receivers } \\
\text { Stimulus for the care } \\
\text { receivers } \\
\text { To create more time with } \\
\text { the care receivers }\end{array}$ & $\begin{array}{l}\text { Reduce care work burden } \\
\text { Ease documentation } \\
\text { Surveillance and } \\
\text { supervision of care } \\
\text { receivers } \\
\text { Reduce work-related } \\
\text { injuries } \\
\text { Can help with cooking, } \\
\text { cleaning and heavy lifts } \\
\text { Free up time for care } \\
\text { receivers } \\
\text { Support care receives as } \\
\text { social stimuli }\end{array}$ \\
\hline Threat to quality of care & $\begin{array}{l}\text { Mechanical care } \\
\text { "Over reliance" of robots } \\
\text { in elder- and healthcare } \\
\text { The word "robot" }\end{array}$ & Patient safety & $\begin{array}{l}\text { Absence of human touch } \\
\text { Would lead to isolation } \\
\text { for the care receivers } \\
\text { Unclear requirements of } \\
\text { care receivers need in } \\
\text { relation to care robots }\end{array}$ & $\begin{array}{l}\text { Decreased human contact } \\
\text { and interaction } \\
\text { Negative feelings against } \\
\text { care robots } \\
\text { The use of care robots } \\
\text { perceived as dangerous } \\
\text { for patient and staff } \\
\text { Harm patients }\end{array}$ \\
\hline
\end{tabular}

- What happens if the robot bumps into furniture and damages it?

- Who will pay for the damage?

- What happens if the robot runs amok?

- What happens when complex robotic solutions do not work? Who is then responsible and who will help handle the problems?

Moreover, the word 'robot' provoked negative feelings among the older participants. The concept of a care robot was associated with automation and the replacement of humans, which made them feel uncomfortable and uneasy. It was suggested that the word 'aid' or 'mechanic help' might be better to use because it implied a supplement to humans instead of a replacement.

The line managers worried about how responsibilities would be divided and shared with the suppliers of the care robots. Among line managers, care robots raised questions about security, information management and responsibility:

- Is there confidentiality in the data collected by care robots at home or at care facilities?

- Who owns the data and who uses it?

- What happens if the robot is hacked or malfunctions and the data collected is used for decision making?

- Can it give incorrect diagnoses or lead to incorrect decisions?
The line managers also raised concerns about a lack of technological skills and competence among frontline care staff, who were seen as a source of resistance against new technology:

We have a lot of frontline care personnel who have worked in home care for more than twenty years. They are not technologically savvy; they do not even read emails or open attachments. They refuse to use technological aids even though the management expects them to do it...they just come up with excuses for not to using technological aids...they won't change because they are too negative towards technology...they act on basis of this negative mentality and look for evidence that confirms that technology usage is negative for the patients. (Line manager, age 52, male)

\subsubsection{Success Criteria for Robots being used in Care}

The participants also mentioned success criteria for robots being used in care. The older participants stressed that they could be interested and motivated to learn how to use a robot if it appeared to have meaningful benefits. The costs of buying or leasing a robot was also a consideration, as was the robot's size and appearance. Likewise, older participants also desired training to ensure safe handling of the robot, in addition to support in the case of unanticipated events. However, noone expressed an urgent need of a care robot at present, nor 
had anyone yet seen or heard of a robot that appeared to correspond to their needs.

Frontline care personnel mentioned they would consider using care robots if they had personal interest and motivation, or if the robot offered greater usefulness. For example, if using a particular care robot could free up time for staff to spend on the care receivers, or if the robot would simplify care work by helping out with cleaning or heavy lifting, it could be considered useful. One frontline care personnel said:

If you have a personal interest and motivation to use a care robot, you would try to learn how to use it and convince the care receivers that care robots are beneficial. (Frontline care personnel, age 36, female)

Widespread adoption of the technology in care situations might affect the will to use care robots among students. The students mentioned that they might use care robots if it was expected from their peers, care receivers and/or line managers, and if they were under pressure, strain or stress. They were not interested in being early adopters of the technology, but if care robots were commonly used and if they were familiar with using them, then they would use the care robots if they were useful. The students also stressed that the care robots needed to be low-cost so that they were extra aids for doing care work, so that funds were not channelled from something that would be spent on human caregivers or investments in improved working conditions.

Training and education were considered important among frontline care personnel and students: know-how and competence would affect their behaviour and attitudes positively toward care robots. If they had better understandings and more knowledge about in which situations care robots could be used, they would be more accommodating towards the robots. Frontline care personnel mentioned that encouragement from management and an appropriate organisational structure to support the use of care robots, in addition to incentives to use care robots in everyday work practices, would have a positive effect on their behaviour and attitude towards care robots.

The line managers showed an optimism towards care robots that was very much in line with the Swedish government's vision of digital transformation [89]. This envisions Sweden as a world leader in utilizing eHealth and digitalisation to promote equity in healthcare and social services by 2025 . The vision promotes self-management and selfcare, and states that responsibility for one's health should be directed to the patient. The line managers expressed willingness towards implementing care robots if they had the financial means, and if the head management and politicians gave clear direction and strategic deliberation regarding care robots. Evidence of care robots' effect on the quality of care and the improvement of working conditions, as well as rules and guidelines that support the implementation of care robots, would further support their drive to use and implement the technology. However, issues such as lack of political direction, lack of care robots as a priority among the head management and politicians, silo mentality, lack of infrastructure and staff resistance made them uncertain and insecure about the financial risks and the initial investment costs. They feared that if they made a case for care robots to change views among management and politicians, they might be held responsible if the implementation resulted in the waste of resources (Table 4).

\subsection{Care Robot Strategy}

Care robot strategy describes the participants' understanding of why care robots are procured or deployed in care, the expected outcomes and values from an organisational perspective.

\subsubsection{Decrease Cost and Managing Skill Shortage}

Many older participants believed that decreasing the cost of eldercare is the reason why care robots are procured and deployed in care. Among the students and frontline care staff, employment was identified as one the most important issues in regard to care robots: both groups believed care robots would result in reduced staffing. While many talked about their expectations and hopes of meaningful jobs within caregiving, care robots provoked fears and insecurity regarding future job opportunities. The students in particular saw care robots as a threat to future employment.

During the focus groups, the students appeared more emotionally concerned about care robots taking their future jobs than current frontline care staff did. The students' fears and worries affected their preconception of robots, skewing their perception of and attitude towards robots negatively; as a result, they showed resentment towards care robots. One of the students said:

I did not do very well in high school, my grades only made it possible to study to become frontline care personnel. I thought that by studying care, I always would have a job and never be unemployed but now care robots might replace me. One of the reasons I study to become frontline care personnel is that I want to work with people not technology. I hate care robots. I will never ever use one. They make me feel worthless. (Student, age 17 , female)

Employment and career prospects were also important among line managers. However, they did not share the students' and frontline care staff's worries about care robots taking their jobs; instead they felt the pressure of working in an understaffed care organisation setting. From their point 
Table 4 Technological frames and care robots in use: participants' assumptions, expectations and understandings of how they will use care robots

\begin{tabular}{|c|c|c|c|c|}
\hline Care Robots in use & Older people & Line managers & Frontline care staff & $\begin{array}{l}\text { Students who are training } \\
\text { to become frontline care } \\
\text { staff }\end{array}$ \\
\hline $\begin{array}{l}\text { The feeling of lack of } \\
\text { control }\end{array}$ & $\begin{array}{l}\text { Reliability } \\
\text { Safety } \\
\text { Question of responsibility } \\
\text { Vulnerability and } \\
\quad \text { dependency }\end{array}$ & $\begin{array}{l}\text { Information management } \\
\text { Question of responsibility } \\
\text { Lack of knowledge and } \\
\text { competence } \\
\text { Staff resistance } \\
\text { Financial risks } \\
\text { Waste of resources } \\
\text { Lack of political } \\
\text { directions } \\
\text { Silo mentality } \\
\text { Lack of priority } \\
\text { Lack of digital } \\
\text { infrastructure }\end{array}$ & $\begin{array}{l}\text { Misfocus } \\
\text { Care practice dependence } \\
\text { of technology and } \\
\text { robots } \\
\text { Lack of time } \\
\text { Lack of resources } \\
\text { Misuse } \\
\text { Lack of knowledge and } \\
\text { competence } \\
\text { Negativity } \\
\text { Inexperience } \\
\text { Malfunction }\end{array}$ & $\begin{array}{l}\text { Technology hassle } \\
\text { Insecurity } \\
\text { Afraid of making } \\
\text { mistakes } \\
\text { Lack of competence and } \\
\text { knowledge } \\
\text { Denial } \\
\text { Malfunction } \\
\text { Hacking } \\
\text { Anxiety }\end{array}$ \\
\hline $\begin{array}{l}\text { Success criteria for care } \\
\text { robots being used }\end{array}$ & $\begin{array}{l}\text { Practical handling and } \\
\text { usability } \\
\text { Needs/purpose } \\
\text { Technology interest } \\
\text { Finances } \\
\text { Availability } \\
\text { Costs } \\
\text { Size and appearance } \\
\text { Ease of use } \\
\text { Training and support }\end{array}$ & $\begin{array}{l}\text { Political directions } \\
\text { Rules and guidelines that } \\
\text { supports the } \\
\text { implementation and use } \\
\text { of care robots } \\
\text { Strategic deliberations } \\
\text { Economic opportunities } \\
\text { Forward planning } \\
\text { Proof of evidence }\end{array}$ & $\begin{array}{l}\text { Technological } \\
\text { possibilities } \\
\text { Personal interest and } \\
\text { motivation } \\
\text { Competence and skills } \\
\text { development } \\
\text { Comprehensions } \\
\text { Encouragement from } \\
\text { management } \\
\text { Incentives } \\
\text { Appropriate } \\
\text { organisational structure }\end{array}$ & $\begin{array}{l}\text { Low-cost } \\
\text { Widespread use of care } \\
\text { robots } \\
\text { Purposive use } \\
\text { Training and education } \\
\text { Pressure, strain and stress }\end{array}$ \\
\hline
\end{tabular}

Table 5 Technological frames and care robot strategy

\begin{tabular}{lllll}
\hline Care Robot Strategy & Older people & Line managers & Frontline care staff & $\begin{array}{l}\text { Students who are training to } \\
\text { become frontline care staff }\end{array}$ \\
\hline & $\begin{array}{l}\text { Decreased costs for elder- and } \\
\text { healthcare }\end{array}$ & Manging skills shortages & Reduced staffing & Reduce staffing \\
\hline
\end{tabular}

of view, care robots might help to decrease the worries of failing to recruit trained frontline care staff (Table 5).

\section{Discussion}

This study examined the assumptions, expectations and understanding of care robots among prospective end-users such as line managers, frontline care staff, older people and students. The aims of the study were: (1) to gain knowledge about how prospective end-users understand and interpret care robots; (2) to explore how potential end users make sense of care robots, and if the assumptions, expectations and understandings within the participating groups are sufficiently congruent for line managers, frontline care staff, older people and students to be conceived as homogenous social groups; (3) to frame the problem space and determine a course of action to address the issues facing implementation and acceptance of care robots in care practices. Orlikowski and Gash's (1994) concept of "technological frames" was used to analyse and understand the data [24].

\subsection{Congruent and Incongruent Frames of Care Robots}

There were congruent frames between the groups regarding assumptions, expectations and understandings about the nature of care robots. This was exemplified by the participants' images of care robots and their understandings of care robots' functionalities and capacities. Care robots were seen as a substitute to humans and human care. The assumptions were that care robots could improve the efficiency of care for care receivers, and support care workers. However, incongruent frames of the nature of care robots become apparent when the participants were asked to sketch their ideal robot. The sketches of care robots illustrated the group of participants' 
assumptions, expectations and understandings of what is possible: their hopes and wishes regarding care robots. While the older participants designed servant robots that could assist with everyday activities, the students and frontline care workers designed robotic co-workers that could do the same tasks as they do, and the line managers designed robots that could perform quality assurance, surveillance and documentation. The sketches suggests that how individuals make sense of technology is a matter of how the individual understands herself in relation to the technology, past experiences, the work organisation and what is perceived as important [57].

The nature of care robots (i.e. the participants' images of care robots and their understandings of care robot's functionality and capacity) also seemed to be a threat to the perception of quality of care, especially among older people, students and frontline care staff. Quality of care was seen as being closely linked to how well-attuned the care worker is to the care receiver's needs. The participants emphasised that caregivers have to remain flexible and adaptive, thinking and acting in tune with a particular care situation and an individual care receiver. Good care was seen as the result of work experience and knowledge about the individual in care, reinforcing the care receivers capability and independence as much as possible, neither neglecting nor over-protecting. The logic of quality of care appeared to be part of the participants' identity as care workers and care receivers. These identities and the participants' perception of quality of care in contrasted to the perception of care robots as a substitute to humans, revealing ambivalence in the technological frame of the nature of care robots. In line with other research [1, 90-92], the participants in the study questioned the quality of care provided by care robots. Concerns about increased mechanical care, an absence of human touch and detachment were raised. Concerns about mechanical care have also been highlighted by researchers (Bekey 2012; Lehoux and Grimard 2018; Sharkey and Sharkey 2012; Sparrow and Sparrow 2006; Turkle 2017; Vallor 2011). Assumptions, expectations and understandings of quality of care in regard to how the participants made sense of the nature of care robots, might inhibit the acceptance of care robots in care of people of age. The technological frame of the nature of care robots showed incongruence and contradictions across all groups, which to quote Sobreperez (2008) "thus signal where adjustments should be made to perceptions, opinions, and mind-sets" [93]. The discrepancies may otherwise lead to consequences such as resistance or noncompliance with the use of care robots in care work [93].

The views of care robots as a threat to quality of care appears to reflect a distrust in the health and care system. This becomes apparent in the technological frame of care robot strategy, where incongruence between students and frontline care staff versus line managers may indicate a conflicted relationship between care staff and how they perceived the management's intentions with care robots. Older people believe that care robots are developed for and deployed in care with the intention to decrease healthcare costs. The students and frontline care staff believed that care robots are developed and deployed with the intention to replace them or at least to reduce staffing. The threat of unemployment as a care worker is not likely, due to the need for care workers [94]. However, unemployment was perceived as a real threat among the frontline care staff and students. As in the design sketch exercise, this shows how individuals' understanding of themselves in relation to the technology and the work organisation affects how they make sense of technology and care robot strategy [57]. In this sense, self-efficacy both shapes and is shaped by technological frames. The students and frontline care staff did not trust the management and leadership: they believed that they did valuable care work but that the management focused more on cost efficiency than quality of care for care receivers. Thus, they believed that the management wanted to replace them with care robots to keep the costs of care down even though it might affect the quality of care. The line managers, on the other hand, who are part of the higher power structures of the care organisations, did not feel threatened by care robots. Instead they perceived care robots as a solution to the shortage of skilled care staff. The incongruence in the technological frame of robot strategy points toward a power conflict between care staff and the management. The frontline care staff, the students and older people, who are in the least powerful positions, felt that care robots may be imposed on them. The management perceived care robots to be one solution to solve the crisis of shortage of care staff. These different understandings, priorities and goals lead to incongruence in the technological frame of care robot strategy, which may result in conflicts, controversy and in worst case that care workers resign, and in fewer training to become frontline care staff $[95,96]$.

Regarding the participants' understanding of how they will use care robots at work or at home, i.e. robots in use, all of the participants expressed a need for more awareness and knowledge about care robots. The older participants, the frontline care staff and the students questioned their own technical ability to be able to handle care robots and expressed that the development was outside of their control. Most of the participants expressed a lack of confidence that care robots would empower them; instead, they thought care robots would result in uncertainties and insecurity due to malfunctions and technical issues. As a result, they feared that attention and resources would be diverted from care to troubleshooting problems with the technology.

The results show that there are contradictions between the rhetoric surrounding care robots in media and how prospective end-users make sense of care robots [97]. High and sometimes unrealistic expectations of care robots were 
observed among all groups of participants in the focus groups. Most had preconceived notions based on their imagination rather than hands-on experience with care robots. The participants had problems distinguishing current advances in care robotics and what care robots are actually able to do (i.e. behave and perform as humans do). Unfortunately, these misinterpretations resulted in ambivalence among students, frontline care staff and older people. On one hand, care robots were seen as a force to decrease costs and increase efficiency in eldercare delivery. On the other hand, care robots were perceived as a threat to quality of care and future employment. Similar views have been disseminated in mainstream media for over a decade [98] and by authors [99-101]. Speculative debates, hype and hopes in the media regarding robots seemed to impact the participants' preconceived notions of care robots.

\subsection{Course of Action: How do we go From Here Towards Increasing Adoption of Care Robots?}

This study identified perceived success criteria that may have a positive influence on the diffusion, adoption and use of care robots. The success criteria may be viewed as a way toward forming congruent technological frames of care robots in care work. As Orlikowski and Gash (1994) suggest, the ultimate diffusion and adoption of new technology is the result of frame congruence, where frames of relevant social groups are related and aligned in structure and content [24]. As diffusion and adoption of a technology is not a linear process but an interpretive and iterative process $[24,55,63,102]$, incongruent technological frames among different end-user groups can change to congruent technological frames in response and adaption to training, new experiences, insights or knowledge and in concurrence with new care practices. Technological frames are continuously reproduced and altered [103]. As such, an understanding of the perceived success criteria for care robots in use among relevant end-user groups and by aligning technological development accordingly, may lead to successful implementation.

If the aim among the management of eldercare organisations and care robot developers, is that care robots ought to be accepted and adopted into care practice, it is necessary to discern what is important (quality of care, the feeling of being in control and employment), and how to take heed of prospective end-users' fears and imaginaries of care robots, i.e. a strategy that considers end-users concerns and expectations [97, 104, 105]. The findings in this paper highlight that the end-user groups we included lack knowledge about care robots and have no training or experience in using them. However, imaginaries, assumptions and expectations may change over time in response and adaption to new experiences, insights or knowledge. Participants across all end-user groups indicated that availability, ease of use and widespread use of care robots would affect their motivation for using care robots. Furthermore, the end-user groups highlighted the need for training and competence: end users need training and hands-on experience of care robots in order to change their technological frames.

For care robots to be used in care practice, available and appropriate care robots are required (which is not the case today), in addition to incentives for using care robots, as well as organisational structures to support the use of care robots. Furthermore, the perception of robots being a threat to the quality of care and further employment need to be addressed.

According to Aiken (2002) the real threat to quality of care is not care robots per see but the lack of trained care workers [106]. In order to address the lack of care workers, care work needs to become more attractive. Care robots can be developed and deployed as means to improve the quality of care of care receivers and as means of improving working conditions for care workers [4]. It has been argued elsewhere that involving the intended users in a participatory design process might help overcome conflicting values of developers and end users, and might enable bridging the gap between the supply of care robots and the demands of end users [107, 108]. End-users of care robots need to understand why they should use care robots, they need to know what kind of care robot to use and in which situation, and they need to know how to use it: know-why, know-what and know-how [109]. A user-centred design framework may be beneficially adopted when introducing new technology into work organisations [110,111]. Similarly, the implementation and deployment of care robots may be user-centred, which is characterised by iterative processes involving the user and knowledge of the context of use in all stages of the design process.

The social practice perspective [21], highlights that technology usage is integrated in social processes and shared conventions. Through this lens, caregiving is a dynamic and elastic practice, constituting materials (technologies, objects and infrastructures), competences (skills and know-how), images (meanings, ideas and interpretations) and connections [26]. As such, caregiving is routine behaviour, affected both by agencies and structures, involving bodily activity, mental activity, technologies and their use [112]. Practices do not change by using a technology per se, rather technology usage evolves by changes, rearrangements and readjustments of the connections to other practices, as well as of transitions of materials, competences and images that constitutes the practice in question. As Orlikowski and Gash (1994) highlight, and in alignment with the social shaping of technology perspective, a collective congruent technological frame is desirable, in order for an organisation to change technical practice or adapt a new technology [24]. Here living 
labs may be a useful tool [113]. Living labs are sites to design, test and learn about new technologies in order to respond to particular societal, political and economic issues [114]. Living labs enable experimentation and exploration of new technologies such as care robots by involving a broad range of stakeholders like companies, universities, care organisations, older people and civil society. This may be a way to remedy incongruent technological frames of care robots, by providing the necessary space to gain knowledge and among different stakeholders and thereby contribute to transformative changes in care practices and care robots' usages.

\subsection{Limitations}

The identified technological frames are not to be considered stable over time, rather they are subject to continuous reproduction and changes in response and adaptation to new experiences, insights or knowledge, and changed values and norms in society.

The study used convenience sampling, and participation in the focus groups and workshops was affected by factors such as curiosity and time availability. Another limitation is that the study was conducted in one location in Sweden; assumptions, expectations and understandings of care robots may differ based on the cultural setting [64].

By using focus group methodology, the results represent a snapshot of assumptions, expectations and understandings of care robots among line managers, frontline care staff, older people and students training to become carers, and cannot be generalised to the entire population or to all potential endusers of care robots. Another limitation of this study is that desires can easily be interpreted as needs. The results could be subject to a group thinking bias, which is one of the disadvantages of using the focus group methodology [77, 80]. While homogeneous groups were used in the current study, in the future it would be worthwhile to explore whether the results are affected by using mixed groups of participants.

\section{Conclusion}

Technological frames connect to the societal acceptance of care robots, power issues and the transformation of care practices, and congruent technological frames of care robots can be a way towards increased adoption and diffusion of care robots. For this reason, it is important to explore assumptions, expectations and understandings of care robots among endusers. The results show how perceptions of care robots are constructed by implicit and incorporated knowledge in care practices. The participants' technological frames appear to be in line with the technological imperative: that care robots are a technological fix to overcome the challenges faced by eldercare, such as increasing costs and meeting the needs of an ageing population.

The technological frame of the nature of care robots as a substitute for humans and human caregiving reflected participants' beliefs and understandings with regard to quality of care, being in control and employment, and affected their willingness to accept care robots. If the aim is the adoption of care robots as suggested by technological deterministic rhetoric, efforts should be made to support care practitioners through training and increased competence in using care robots (skills and know-how), to overcome feelings of inadequacy and to create congruent collective technological frames among these end-user groups. Furthermore, incentives for using care robots, as well as organisational structures to support the use of care robots (objects and infrastructure), and expectations among all stakeholders that care robots are used as part of care practices (meaning, ideas and interpretations) are desirable.

The importance of hands-on experience in working with care robots and promoting increased awareness and education about what care robots can do is necessary in order to move away from preconceptions based on fiction and imaginaries of care robots and incongruent technological frames.

Acknowledgements Open access funding provided by Malmö University. The research is carried out as part of the INBOTS project (Grant agreement No. 780073), which is funded by the European Union. The authors would like to thank the participants who voluntarily participated in the focus groups and who shared their views on care robots.

Open Access This article is licensed under a Creative Commons Attribution 4.0 International License, which permits use, sharing, adaptation, distribution and reproduction in any medium or format, as long as you give appropriate credit to the original author(s) and the source, provide a link to the Creative Commons licence, and indicate if changes were made. The images or other third party material in this article are included in the article's Creative Commons licence, unless indicated otherwise in a credit line to the material. If material is not included in the article's Creative Commons licence and your intended use is not permitted by statutory regulation or exceeds the permitted use, you will need to obtain permission directly from the copyright holder. To view a copy of this licence, visit http://creativecomm ons.org/licenses/by/4.0/.

\section{References}

1. Archibald M, Barnard A (2018) Futurism in nursing: technology, robotics and the fundamentals of care. J Clin Nurs 27(11-12):2473-2480

2. Thorslund M (2011) Åldrandet och äldreomsorgens utveckling [Aging and eldercare development]. Socialmedicinsk tidskrift 87(5-6):397-406

3. Riek LD (2017) Healthcare robotics. Commun ACM 60(11):68-78

4. Lehoux P, Grimard D (2018) When robots care: Public deliberations on how technology and humans may support independent living for older adults. Soc Sci Med 211:330-337 
5. Robinson H, MacDonald B, Broadbent E (2014) The role of healthcare robots for older people at home: A review. Int J Soc Robot 6(4):575-591

6. Wada K, et al (2005) Psychological and social effects of one year robot assisted activity on elderly people at a health service facility for the aged. In: Proceedings of the 2005 IEEE international conference on robotics and automation 2005, ICRA 2005. IEEE

7. Matarić MJ et al (2007) Socially assistive robotics for post-stroke rehabilitation. J NeuroEng Rehabil 4(1):5

8. Mordoch E et al (2013) Use of social commitment robots in the care of elderly people with dementia: a literature review. Maturitas 74(1):14-20

9. Wilson JR, Tickle-Degnen L, Scheutz M (2016) Designing a social robot to assist in medication sorting. In: International conference on social robotics. Springer, Japan

10. Bedaf $\mathrm{S}$ et al (2018) A multi-perspective evaluation of a service robot for seniors: the voice of different stakeholders. Disabil Rehabil Assist Technol 13:592-599

11. Bechtold U, Capari L, Gudowsky N (2017) Futures of ageing and technology-comparing different actors' prospective views. J Responsible Innov 4(2):157-176

12. Pearce AJ et al (2012) Robotics to enable older adults to remain living at home. J Aging Res. 2012:10

13. Mol A (2008) The logic of care: health and the problem of patient choice. Routledge, London

14. Greenhalgh T, Russell J (2010) Why do evaluations of eHealth programs fail? An alternative set of guiding principles. PLoS Medicine 7(11):e1000360

15. Greenhalgh $\mathrm{T}$ et al (2013) What matters to older people with assisted living needs? A phenomenological analysis of the use and non-use of telehealth and telecare. Soc Sci Med 93:86-94

16. Gelbrich K, Sattler B (2014) Anxiety, crowding, and time pressure in public self-service technology acceptance. J Serv Mark 28(1):82-94

17. Cazan A-M, Cocoradă E, Maican CI (2016) Computer anxiety and attitudes towards the computer and the internet with Romanian high-school and university students. Comput Hum Behav 55:258-267

18. Martínez-Torres MDR et al (2015) The moderating role of prior experience in technological acceptance models for ubiquitous computing services in urban environments. Technol Forecast Social Change 91:146-160

19. Plötz P et al (2014) Who will buy electric vehicles? Identifying early adopters in Germany. Transp Res Part A Policy Pract 67:96-109

20. Suchman L, Wynn E (1984) Procedures and problems in the office. Off Technol People 2(2):133-154

21. Shove E, Pantzar M, Watson M (2012) The dynamics of social practice: Everyday life and how it changes. Sage Publication, London

22. Cherns A (1976) The principles of sociotechnical design. Hum Relat 29(8):783-792

23. Bohgard M, Karlsson S, Lovén E, Mikaelsson LÅ, Mårtensson L, Osvalder AL, Rose L, Ulfvengren P (2009) Work and technology on human terms. Prevent, Stockholm, Sweden

24. Orlikowski WJ, Gash DC (1994) Technological frames: making sense of information technology in organizations. ACM Trans Inf Syst (TOIS) 12(2):174-207

25. Sovacool BK, Hess D (2017) Ordering theories: typologies and conceptual frameworks for sociotechnical change. Soc Stud Sci 47(5):703-750

26. Shove E, Trentmann F, Wilk R (2009) Time, consumption and everyday life: practice, materiality and culture. Berg, Oxford

27. Brandt E, et al. (2010) Communities of everyday practice and situated elderliness as an approach to co-design for senior interaction. In: Proceedings of the 22 nd conference of the computer-human interaction special interest group of Australia on computer-human interaction. ACM

28. Nicolini D (2016) Knowing in Organizations: a practice-based approach: Routledge, Abingdon

29. Nilsen ER et al (2016) Exploring resistance to implementation of welfare technology in municipal healthcare services-a longitudinal case study. BMC Health Serv Res 16(1):657

30. Blaschke CM, Freddolino PP, Mullen EE (2009) Ageing and technology: a review of the research literature. Br J Soc Work 39(4):641-656

31. Sandelowski M (1999) Troubling distinctions: a semiotics of the nursing/technology relationship. Nurs Inq 6(3):198-207

32. Sandelowski M (2002) Visible humans, vanishing bodies, and virtual nursing: complications of life, presence, place, and identity. Adv Nurs Sci 24(3):58-70

33. Sandelowski M (1999) Culture, conceptive technology, and nursing. Int J Nurs Stud 36(1):13-20

34. Frennert S, Östlund B (2014) Seven matters of concern of social robots and older people. Int J Soc Robot 6(2):299-310

35. Neven L (2010) 'But obviously not for me': robots, laboratories and the defiant identity of elder test users. Soc Health Illn 32(2):335-347

36. Hofmann B (2013) Ethical challenges with welfare technology: a review of the literature. Sci Eng Ethics 19(2):389-406

37. Davis FD (1989) Perceived usefulness, perceived ease of use, and user acceptance of information technology. MIS Q 13(3):319-339

38. Rogers EM (2010) Diffusion of innovations. Simon and Schuster, New York

39. Bekey GA (2005) Autonomous robots: from biological inspiration to implementation and control. MIT press, Cambridge

40. Vallor S (2011) Carebots and caregivers: sustaining the ethical ideal of care in the twenty-first century. Philosophy Technology 24(3):251

41. Laitinen A, Niemelä M, Pirhonen J (2016) Social robotics, elderly care, and human dignity: a recognition-theoretical approach. Proc Robophilosophy/TRANSOR 290:155

42. Klein B, Gaedt L, Cook G (2013) Emotional robots. GeroPsych 26(2):89-99

43. Tergesen A, Inada M (2010) It's not a stuffed animal, it's a $\$ 6,000$ medical device. The Wall Str J 6(21):1

44. Broadbent $\mathrm{E}$ et al (2010) Attitudes and reactions to a healthcare robot. Telemed e-Health 16(5):608-613

45. Broadbent E, et al (2014) Robots in older people's homes to improve medication adherence and quality of life: a randomised cross-over trial. In: International conference on social robotics. Springer

46. Union E (2015) Special Eurobarometer 427 "Autonomous systems", C.a.T.D.C. Directorate-General for Communications Networks, Editor. http://ec.europa.eu/public_opinion/index_en.htm

47. Jenkins S, Draper H (2014) Robots and the division of healthcare responsibilities in the homes of older people. In: International conference on social robotics. Springer, Cham

48. Abdi J et al (2018) Scoping review on the use of socially assistive robot technology in elderly care. BMJ Open 8(2):e018815

49. Verbeek P-P (2015) Beyond interaction: a short introduction to mediation theory. Interactions 22(3):26-31

50. Verbeek P-P (2006) Materializing morality: design ethics and technological mediation. Sci Technol Human Values 31(3):361-380

51. Borup $\mathrm{M}$ et al (2006) The sociology of expectations in science and technology. Technol Anal Strateg Manag 18(3-4):285-298

52. Verbeek P-P (2015) Toward a theory of technological mediation. Technoscience and Postphenomenology, The Manhattan, pp 189-204

53. Kudina O (2019) The technological mediation of morality: value dynamism, and the complex interaction between ethics and tech- 
nology. University of Twente, Enschede. https://doi.org/10.3990/ 1.9789036547444

54. Kudina O, Verbeek P-P (2019) Ethics from within: Google Glass, the Collingridge dilemma, and the mediated value of privacy. Sci Technol Human Values 44(2):291-314

55. MacKenzie D, Wajcman J (1999) The social shaping of technology. Open University Press, London

56. Eccles JS, Wigfield A (2002) Motivational beliefs, values, and goals. Annu Rev Psychol 53(1):109-132

57. Weick KE (1995) Sensemaking in organizations, vol 3. Sage, London

58. Ingold T, Kurttila T (2000) Perceiving the environment in Finnish Lapland. Body Soc 6(3-4):183-196

59. Latour B (2005) Reassembling the social: an introduction to actornetwork-theory. Clarendon, Oxford

60. Norman DA (1999) Affordance, conventions, and design. Interactions 6(3):38-43

61. Wenger E (1999) Communities of practice: learning, meaning, and identity. Cambridge University Press, Cambridge

62. Orlikowski WJ (1992) The duality of technology: rethinking the concept of technology in organizations. Organ Sci 3(3):398-427

63. Bijker WE (1997) Of bicycles, bakelites, and bulbs: toward a theory of sociotechnical change. MIT press, Cambridge

64. Coco K, Kangasniemi M, Rantanen T (2018) Care personnel's attitudes and fears toward care robots in elderly care: a comparison of data from the care personnel in Finland and Japan. J Nurs Scholarsh 50(6):634-644

65. Rantanen $\mathrm{T}$ et al (2018) Attitudes towards care robots among Finnish home care personnel-a comparison of two approaches. Scand J Caring Sci 32(2):772-782

66. Mavridis $\mathrm{N}$ et al (2012) Opinions and attitudes toward humanoid robots in the Middle East. AI Soc 27(4):517-534

67. Gómez JV, Mavridis N, Garrido S (2013) Social path planning: Generic human-robot interaction framework for robotic navigation tasks. In: 2nd Intl. workshop on cognitive robotics systems: replicating human actions and activities

68. Haraway D (2003) Situated knowledges: the science question in feminism and the privilege of partial perspective. Turn Points Qual Res Tying Knots Handkerchief, 2003:21-46

69. Salzmann-Erikson M, Eriksson H (2018) A descriptive statistical analysis of volume, visibility and attitudes regarding nursing and care robots in social media. Contemp Nurse 54(1):88-96

70. Papadopoulos I, Koulouglioti C, Ali S (2018) Views of nurses and other health and social care workers on the use of assistive humanoid and animal-like robots in health and social care: a scoping review. Contemp Nurse 54(4-5):425-442

71. Tuisku O et al (2019) "Robots do not replace a nurse with a beating heart" the publicity around a robotic innovation in elderly care. Inf Technol People 32(1):47-67

72. Berger PL, Luckmann T (1991) The social construction of reality: a treatise in the sociology of knowledge. Penguin, London

73. Flyvbjerg B (2005) Social science that matters. Foresight Eur 2:38-42

74. Goodman LA (1961) Snowball sampling. Ann Math stat 32(1):148-170

75. Harrison K, Barlow J (1995) Focused group discussion: a "quality" method for health research. Health Psychol Update 20:11-13

76. Vaughn S, Schumm JS, Sinagub JM (1996) Focus group interviews in education and psychology. Sage Publications, Thousands Oaks

77. Curtis EA, Redmond R (2007) Focus groups in nursing research. Nurse Res 14(2):25

78. Jayasekara RS (2012) Focus groups in nursing research: methodological perspectives. Nurs Outlook 60(6):411-416
79. Field J (2000) Researching lifelong learning through focus groups. J Furth High Educ 24(3):323-335

80. Krueger RA (2014) Focus groups: a practical guide for applied research. Sage Publications, London

81. Morgan DL (1997) The focus group guidebook, vol 1. Sage publications, London

82. Morgan DLR, Krueger R (1993) When to use focus groups and why. In: Morgan DL (ed) Successful focus groups: advancing the state of the art, vol 1. Sage Publication, Thousand Oaks, Ca, pp 3-19

83. Clarke A (1999) Focus group interviews in health-care research. Prof Nurse 14(6):395-397

84. Granskär M, Höglund-Nielsen B (2012) Tillämpad kvalitativ forskning inom hälso-och sjukvård [Applied qualitative research in healthcare]. Studentlitteratur, Stockholm, Sweden

85. Richards L, Morse JM (2012) Readme first for a user's guide to qualitative methods. Sage, London

86. Krippendorff K (2011) Agreement and information in the reliability of coding. Commun Methods Measures 5(2):93-112

87. Council SR (2017) Good research practice. Swedish Research Council, Stockholm

88. Hem MH, Halvorsen K, Nortvedt P (2014) Altruism and mature care: some rival moral considerations in care ethics. Nursing Ethics 21(7):794-802

89. Wickström G, Regner Å, Micko L (2017) Vision eHealth 2025 common starting points for digitization in social services and health and medical care. Ministry of Health and Social Affairs, Stockholm

90. Sparrow R, Sparrow L (2006) In the hands of machines? The future of aged care. Minds Mach 16(2):141-161

91. Turkle S (2017) Alone together: Why we expect more from technology and less from each other. Basic Books, New York

92. Coeckelbergh M (2015) Artificial agents, good care, and modernity. Theor Med Bioeth 36(4):265-277

93. Sobreperez P (2008) Technological frame incongruence, diffusion, and noncompliance. In: IFIP working conference on open IT-based innovation: moving towards cooperative IT transfer and knowledge diffusion. Springer

94. Jackson DE, Mannix J, Daly J (2003) Nursing staff shortages: issues in Australian residential aged care. Austr J Adv Nursing

95. Latzko-Toth $G$ et al (2019) Misuser innovations: the role of "misuses" and "misusers" in digital communication technologies. Field Guide Sci Technol Stud, Digitalsts, p 393

96. Gilleard C (2017) The place of age in the digital revolution. Digital technologies and generational identity. Routledge, Abingdon, pp $11-22$

97. Whiteman G, Cooper WH (2011) Ecological sensemaking. Acad Manag J 54(5):889-911

98. Fleming G (2009) Nurses will be replaced by evil robots-you have been warned [Internet]. Nursing Times, London

99. Parks JA (2010) Lifting the burden of women's care work: should robots replace the "human touch"? Hypatia 25(1):100-120

100. Sharkey A, Sharkey N (2012) Granny and the robots: ethical issues in robot care for the elderly. Eth Inf Technol 14(1):27-40

101. Nielsen JA, Andersen KN, Sigh A (2016) Robots conquering local government services: a case study of eldercare in Denmark. Inf Polity 21(2):139-151

102. Hui AE, Schatzki TE, Shove EE (2017) The nexus of practices: connections, constellations, practitioners. Routledge, London

103. Treem JW et al (2015) Bringing technological frames to work: how previous experience with social media shapes the technology's meaning in an organization. J Commun 65(2):396-422 
104. Sun TQ, Medaglia R (2019) Mapping the challenges of artificial intelligence in the public sector: evidence from public healthcare. Gov Inf Q 36(2):368-383

105. Poulsen A, Burmeister OK, Tien D (2018) A new design approach and framework for elderly care robots. In: Australasian conference on information systems, Sydney, Australia

106. Aiken LH et al (2002) Hospital nurse staffing and patient mortality, nurse burnout, and job dissatisfaction. JAMA 288(16): 1987-1993

107. Eftring H, Frennert S (2016) Designing a social and assistive robot for seniorsDesign sozialer Assistenzroboter für ältere Menschen. Zeitschrift für Gerontologie und Geriatrie 49(4):274-281

108. Östlund B et al (2015) STS-inspired design to meet the challenges of modern aging. Welfare technology as a tool to promote user driven innovations or another way to keep older users hostage? Technol Forecast Soc Change 93:82-90

109. Garud R (1997) On the distinction between know-how, knowwhat, and know-why. Adv Strateg Manag 14:81-102

110. Dopp AR et al (2019) Integrating implementation and usercentred design strategies to enhance the impact of health services: protocol from a concept mapping study. Health Res Policy Syst 17(1): 1

111. Lazar $\mathbf{J}$ et al (2016) Human-computer interaction and international public policymaking: a framework for understanding and taking future actions. Found Trends Hum Comput Interact 9(2):69-149

112. Schatzki TR (2002) The site of the social: A philosophical account of the constitution of social life and change. Penn State Press, Pennsylvania

113. Bulkeley H, McCormick K (2018) Governance of urban sustainability transitions: advancing the role of living labs-JPI urban Europe. Impact 2018(4):17-19
114. Bergschöld JM, Neven L, Peine A (2019) DIY gerontechnology: circumventing mismatched technologies and bureaucratic procedure by creating care technologies of one's own. Sociol Health Illn. https://doi.org/10.1111/1467-9566.13012

Publisher's Note Springer Nature remains neutral with regard to jurisdictional claims in published maps and institutional affiliations.

Susanne Frennert is associate professor at the Faculty of Technology and Society at Malmö University. Susanne Frennert's expertise lies in the field of Human Computer Interaction, Human Robot Interaction, Cognitive Science, Human Factors and Participatory Design: involving older people and healthcare professionals in the design process of social robots and healthcare technologies to better match their needs, wants and desires.

Hedvig Aminoff is a doctoral student with a background in cognitive science and professional experience in interaction design. She is currently focusing on usability in design and evaluation of telemedicine in surgical settings.

Britt Östlund Professor at the Royal Institute of Technology, KTH, in Sweden. Since thirty years, dedicated to research and development in aging, technology and design, today focusing digitization of home health care and services. Part of the Swedish Government Advisory Board for Ageing, health and life sciences. 